\title{
ON THE RESEARCH VALUE OF LARGE GAMES: NATURAL EXPERIMENTS IN NORRATH AND CAMELOT
}

\author{
EDWARD CASTRONOVA \\ CESIFO WORKING PAPER NO. 1621 \\ CATEGORY 10: EMPIRICAL AND THEORETICAL METHODS \\ DECEMBER 2005
}

\footnotetext{
An electronic version of the paper may be downloaded

- from the SSRN website: www.SSRN.com

- from the CESifo website: www.CESifo-group.de
} 


\title{
ON THE RESEARCH VALUE OF LARGE GAMES: NATURAL EXPERIMENTS IN NORRATH AND CAMELOT
}

\begin{abstract}
Games like EverQuest and Dark Age of Camelot occasionally produce natural experiments in social science: situations that, through no intent of the designer, offer controlled variations on a phenomenon of theoretical interest. This paper examines two examples, both of which involve the theory of coordination games: 1) the location of markets inside EverQuest, and 2) the selection of battlefields inside Dark Age of Camelot. Coordination game theory is quite important to a number of literatures in political science, economics, sociology, and anthropology, but has had very few direct empirical tests because that would require experimental participation by large numbers of people. The paper argues that games, unlike any other social science research technology, provide for both sufficient participation numbers and careful control of experimental conditions. Games are so well-suited to the latter that, in the two cases we examine, the natural experiments that happened were, in fact, perfectly controlled on every relevant factor, without any intention of the designer. This suggests that large games should be thought of as, in effect, social science research tools on the scale of the supercolliders used by physicists: expensive, but extremely fruitful.
\end{abstract}

JEL Code: L86.

\author{
Edward Castronova \\ Department of Telecommunications \\ Indiana University \\ 1229 E. $7^{\text {th }}$ Street \\ Bloomington, IN 47405 \\ USA \\ castro@indiana.edu
}

11 July 2005. 


\section{Introduction}

This paper attempts to alert the reader to the research potential of large games, games with so many players and such rich complexity as to be hosts for genuine human social interactions. The claim is that such interactions are quite hard to study at the scale of all society. Until now, it has not been possible to take all-of-society as a research object; such a thing is too big to fit in a lab, and the histories it produces are never replicated anywhere. Thus, while we might believe theoretically, historically, and ethnographically, that society operates a certain way, and we might have small-scale experiments that support our beliefs, it has generally not been possible to observe whole societies under controlled conditions. Now, however, with the advent of synthetic world technology, it is indeed possible to replicate entire societies and allow them to operate in parallel. This paper is an exploration of what might be learned from a research program built around such a method. Having no lab (as yet) in which to conduct this kind of experiment, we turn instead to the synthetic worlds that already exist, and ask whether any of them have produced quasi-experiments: situations in which important factors have been controlled, unwittingly, by the designers. Two specific examples of such quasiexperimental circumstances will be put forth, one in EverQuest, by Sony Online Entertainment, and the other in Dark Age of Camelot, by Mythic Entertainment. Both cases involve the theory of coordination games. In what may be the first finding of its kind, these cases provide controlled-experimental evidence on the level of all society, that coordination effects do exert force there. In other words, coordination effects are not just of theoretical importance, and our evidence of them from ethnography, history, and small-scale experiments is not misguided. They are genuinely powerful at the most 
aggregated level of human society. At the same time, the ease and clarity with which they could be observed speaks to the immense value of large games as a research tool, prompting, perhaps, a re-thinking of how social scientists do their business.

The paper has six remaining sections. First I introduce the concept of coordination games and their theorized role in social outcomes. Next, section 2 explains why any current evidence about coordination effects at the macro-social level has to be indirect, and thus fairly unpersuasive. Section 3 puts forth the idea of large games as a new research tool that allows direct, replicable observation of whole societies in operation. Sections 4 and 5 present evidence of coordination by players in the large games EverQuest and Camelot, respectively. Section 6 concludes with a call for a new methodological direction in social research: the use of large games to study behaviors of the whole.

\section{The Power and Fragility of Coordination}

You and a friend go to a large shopping mall but you become separated in the crowds. Neither of you has a phone or any other communication device, and the mall does not have a public address system by which you might page one another. To meet your friend again, where would you go? Or would you go anywhere at all? Perhaps you should stay put and wait for your friend to find you. But what if she does the same thing? On the other hand, if you both decide to go roaming, she will probably pass through the spot you're standing in ten times before you accidentally run into each other. Perhaps you should think about the most likely place she would look, and go there. Maybe the last store she was in. Or the last store that you were in. Or maybe the exit or even the car is the best bet. Maybe the mall has a 'Meeting Point', a spot created just to minimize the 
costs of this dilemma. Suppose you looked at the directory and there was a red dot labeled 'LOST PEOPLE MEET UP HERE'. Well, you could probably bet that she would go there, and therefore, so should you. Furthermore, if she is following the same reasoning, she's going to place a high probability on the red dot too, which will make it her first choice. And - coming back to you now - these guesses of yours about her reasoning further raise the likelihood that the red dot is the place to go. And so: you go to the red dot. And there she is.

The red dot, the Meeting Point, is an example of a coordination equilibrium, a social phenomenon that shares two properties that social phenomena don't often share: Power and Fragility. Power comes from the fact that human coordination saves lots of time and money, and it gets remembered. The next time you and your friend go to the mall, you'll know where you'll meet up if you get lost again: the Red Dot. But if the mall did not have a Red Dot, and you had ended up meeting at, say, the North Exit, then in all likelihood you'd always and forever find one another at the North Exit. Coordination equilibria, also known as focal points, place a structure on our expectations of what others will do, and those expectations of others have an incredibly powerful effect on our choices. I work at Indiana University, and I wear red clothes to the football games. Is it because I like red clothes? No. Is it because the Chancellor will reduce my pay if I wear blue? No. Is it because I want to march in step with my fellow Hoosiers, in perfectly jackbooted style? No. It's because I have observed rude behavior by sports fans in reaction to nonconforming sports attire (all in good fun, but still, it's uncomfortable), and my understanding is that everyone at this particular stadium will be wearing red. If I went to a stadium in Ann Arbor, I'd wear blue. In East Lansing, green. In Evanston, purple. It 
is the culture of sport to coordinate on team colors. And for each team, the color is the focal point, a coordination equilibrium that exerts incredible pressure on hundreds of thousands of people, forcing almost all of them to wear some arbitrary, even ridiculous color (purple?), whether they really want to or not.

There's a second aspect of power worth mentioning. Someone at Indiana University, back in the mists of time, decided that our colors would be red. If you happened to be a red dye maker in Bloomington, that was a happy choice, with immense implications for your business. At the shopping mall, someone decides where the Meeting Point will be. If it happens to be right in front of your store, then that decisionmaker has just directed some traffic to your business. Not every coordination equilibrium happens intentionally, but when someone does choose the focal point, that person exerts influence on human behavior, directing it into specific channels.

And yet this second source of coordination power is also the source of its fragility. In many social situations, there are many conceivable foci. Take colors. You could have red, blue, yellow, green, purple, black, orange, or any of an infinite number of combinations. If one is selected - Red - then all people coordinate to red. Yet the moment that another is selected, and becomes known as the new focal point, the first loses its power completely and utterly. When the St. John’s University basketball team changed their mascot from "Red Men” to "Red Storm”, anyone whose business relied on the native American imagery lost something, while those who made t-shirts with clouds on them gained something. And this can be an instantaneous effect; coordination systems can cause huge flows of well-being in mere seconds. 
Examples other than sports and shopping serve to illustrate the power and fragility of coordination at a somewhat more meaningful level. Governmental power, for one, is a coordination equilibrium. In times of revolution, all of society must determine whom all of society will consider 'The Government'. That is why the putschists seize the radio station - by broadcasting to the entire country that Herman is the new dictator, they instill the expectation that everyone is going to be treating Herman as the new dictator. And if everyone treats Herman as the new dictator, well, he is the new dictator. His orders will be followed, because everyone expects that those who do not follow his orders will be killed. Thus, heads will roll if Herman pulls off this shift in the focal point. His head will roll if he does not. It is often difficult to understand how entire systems of absolute power, such as the Ancien Regime in $18^{\text {th }}$ century France, could be toppled in the course of a few days, but in fact, it's merely the switch from one governing focal point to another. And simple, even localized events, such as the storming of the Bastille or the opening of the Berlin Wall, are sufficient to signal to the entire world that the focal point has changed. Once everyone believes that Parliament, and not the King, has ultimate authority, the Parliament, by virtue of those shared beliefs, does have ultimate authority. The King becomes a mere citizen indeed, subject to the soldiers' orders and not vice versa.

The value of money is another coordination equilibrium. The dollars in our pockets have value because we all expect everyone else to treat them as though they have value. As I write this, the focal point is that one US dollar is worth about one bottle of Coca Cola. That is: I expect that everyone will treat my dollar as though it has the same market value as a bottle of Coke. Factually, and objectively, the dollar has no value 
whatsoever - you can't eat it, you can't write on it, you can't wear it. It's worthless in use. But in exchange, it is worth something, and what it is worth is determined by the coordination equilibrium. If I decided that my dollars were worth two bottles of Coke, not just one, I would be off the equilibrium and would not succeed in any attempt to get people to trade with me. If I decided my dollars were worthless and gave them away for nothing, I would again be off the equilibrium and would find myself dead of starvation fairly quickly. Therefore I (and by extension everyone else) choose to act as though the dollar is worth one Coke, and I can expect that everyone else will as well. From this perspective, inflation can be seen as the gradual shift in the focal point, a kind of massive dance in which all of society unconsciously takes the same step of -3.4 percent in its understanding of what a dollar is worth. This dance is ultimately being done to a rhythm called out by the government, of course. And when the government does a poor job as bandleader, the dance steps get more tricky, larger, and the dance of inflation becomes a terrifying and conscious act, sometimes with dramatic conclusions, such as during the German hyperinflation of 1922-23. Wages were posted not annually but daily, even hourly. A new coordination game erupted around not the value of the money but on the daily percent decline in the value of the money: "How much are we stepping today? I need to align my product prices with my workers’ wages!” A government can beat the drum so quickly that all pensions are wiped out, or that all debts become meaningless, being repayable in a currency worth only a tiny fraction of what it was worth when the debt was incurred. The value of money, like governmental authority and all coordination equilibria, is both powerful, and fragile. 
A third example of the importance of coordination is in media. Take journalism. Once one powerful outlet decides that a story is important, all outlets consider the story important, and they therefore run with it. Thus, from the standpoint of the viewer, it is important. Woe to the outlet that fails to run an important story, or that runs stories that no other outlets think are important. This then drives all the outlets to guess what all the outlets will think is important, a coordination game at the meta level that is only loosely connected to what individual people think is important. And because we, as individuals, have a natural desire to seem 'on top of things' to our peers, it is not at all clear that our own expressions of what is important reflect any internal judgment of relevance. How relevant is it to any one person whether Tom Cruise or Tom Hanks wins the Oscar for Best Male Performer? Yet almost everyone has an opinion, has thought about it. Such a thing is important because it is important. With coordination phenomena, what seems to be circular logic is, in fact, all the logic there is. It is, if you will, a brittle unlogic, and yet quite powerful.

The above examples illustrate that coordination games are an important element of thinking about economics, politics, and culture. We know a great deal about them analytically because of the work of mathematical game theorists. This approach, defined largely by John von Neumann, Oskar Morgenstern, and John Nash, favors formal mathematical expressions of players, strategies, and outcomes, and assumes that players will be rational in their choices of what to do. Perhaps the best overall analysis of coordination games was written by recent Nobel laureate Thomas Schelling: The Strategy of Conflict (1965). 
From Schelling, a coordination game can be expressed as follows. There are two players, 1 and 2. Each player chooses either move X, or move Y. If both choose X, Player 1 receives $M$ as a reward, and Player 2 receives $M+1$ ( $M$ could be dollars or power or puppies - anything the players believe is a good thing). If both choose Y, Player 1 receives $\mathrm{M}+1$, and Player 2 receives just $\mathrm{M}$. If one chooses $\mathrm{X}$ and the other chooses $\mathrm{Y}$, they both receive nothing. This game can be expressed in a choice diagram:

\begin{tabular}{|c|c|c|c|}
\hline & \multicolumn{2}{|c|}{ Player 2} \\
\hline & & Move X & Move Y \\
\hline \multirow{2}{*}{ Player 1} & Move X & $\begin{array}{c}\text { Player } 1: \mathrm{M} \\
\text { Player } 2: \mathrm{M}+1\end{array}$ & 0 for both \\
\hline & Move Y & 0 for both & $\begin{array}{c}\text { Player 1: } \mathrm{M}+1 \\
\text { Player } 2: \mathrm{M}\end{array}$ \\
\hline
\end{tabular}

Diagram 1. A Coordination Game

This simple game exhibits all the essential features of the coordination phenomenon. First, whatever is the thing enumerated by the payoff number M, we have assumed that it is something the players like. Having some of it is better than having none of it. Thus, both players would rather have a coordinated outcome $-\{\mathrm{X}, \mathrm{X}\}$ or $\{\mathrm{Y}, \mathrm{Y}\}$ rather than a mix of the two - because only when they choose the same move do they get anything positive. Yet what is unclear is which of the two coordination points they will choose. And that also matters. If they get together on $\{X, X\}$, Player 2 is going to be slightly better off, getting one more of the good thing. If instead they get together on $\{Y, Y\}$, that's going to be better for Player 1 . Just what they will do depends on other things that determine how the game gets played. For example, suppose Player 1 gets to move first. Her best bet would be to choose Y. If she chooses Y, Player 2 then has the 
choice of $\mathrm{X}$ (receiving nothing) or Y (receiving M). Since M is better than nothing, player 2 chooses $\mathrm{Y}$, thus giving Player $1 \mathrm{M}+1$. You might say that Player 1 "wins” this one. If Player 2 was given the first move, he would "win" because his first move would be $\mathrm{X}$, forcing Player 1 into $\mathrm{X}$ as well.

Another possibility for the structure of the game puts power in the hands of a third person. Suppose the two players cannot talk to one another and they both have to move at the same time. This would be rather like the shopping mall example at the start of the paper. Not having any idea how the other player will move, both players will make some essentially random choice, winding up with one of the four outcomes with about equal probability. Now suppose some third person can talk to both of them. That third person might say "Make Move X” or "Make Move Y" or "Make a random move”. Suppose the third person says " $X$ ". In that case, both players should reasonably conclude that the other player is more likely to do $\mathrm{X}$ than anything else. Therefore $\mathrm{X}$ makes more sense as their own move. And by this same reasoning, $\mathrm{X}$ is seen as a still better move for the other player. And once more, that makes $\mathrm{X}$ yet better again as their own move. The circularity of reasoning reduces to the difficult truth that $\mathrm{X}$ is chosen because $\mathrm{X}$ is chosen. But recall that the system moved to X, and not Y, only because of the third person's statement. This is the analytics behind the Meeting Point and the power of its Big Red Dot to make two friends meet at a certain point in the mall. This also illustrates the power of media to induce behavior, and the power of a dictator to normalize his own power. Through properly constructed and positioned broadcasts, those who own microphones can make the whole world expect a certain behavior, and, because that behavior is expected, it will be performed. 
Another structure for this game illustrates the power of a history. Suppose Player 1 and Player 2 are members of two cultures, Culture 1 and Culture 2, that have been having this kind of interaction for a very long time. Somewhere back in the mists of the past, at a time that no one remembers, it became established that people from both cultures would play Y, giving a slight advantage to members of Culture 1. Every once in awhile, a Culture 2 member might try to upend the apple cart and play $\mathrm{X}$ instead, but in those cases that person always came away empty-handed, because the Culture 1 people always play Y. X and Y give everybody nothing, making it seem fruitless for Culture 2 to try to change things. And yet, those who truly understand this interaction cannot avoid realizing that it could very easily go the other way. But it does not. The heavy hand of history forces Culture 2, bitterly, to accept a disadvantaged outcome. The only way to change things: a revolution in expectations that starts a new history. Only if everyone in Culture 2 and Culture 1 can be made to expect the $\mathrm{X}$ move, will all the players begin making $\mathrm{X}$ moves. On the other hand, all one has to do is change the expectations, and nothing more. If you can change everyone’s mind about what the "normal” move is, suddenly $\mathrm{X}$ becomes the normal move, and Culture 2 becomes the privileged culture.

Coordination games are thus fairly simple to understand analytically, and armchair empiricism suggests that they are prevalent in a number of important social phenomena. In terms of their influence over human affairs, they seem to be both powerful and fragile at the same time. A coordination equilibrium, or focal point, is immensely powerful so long as everyone believes in it. Yet a slight alteration in these beliefs is all it takes to destroy the power of a focal point quite completely. A system with these features creates a very unique pattern of hopes and fears in anyone trying to work within it. 
Changing the collectivity of expectations is at times in one sense impossible, in another sense easy. It seems impossible because people are autonomous - who can change the mind of every person simultaneously? And yet it seems easy because change does not require one to move mountains or harness the sun - you just have to make people have different expectations about one another’s behavior.

\section{Empirical Evidence?}

It would certainly be broadly useful if we knew that this fragile, yet powerful, piece of coordination unlogic was in fact the reigning dynamic behind real world social change. The theory is fairly easy to disbelieve; it defies intuition at a number of levels. I've run through the model with my wife in an attempt to coordinate on a simple plan in the event we get separated in a crowd: she should stay in one spot while I roam around. Or was it, I should stay in one spot while she moves around? When we get lost, you see, I invariably forget what the coordination actually was. And so we roam around more or less aimlessly like all couples do. In other words, it’s not clear that real people are as rational and mindful as the theory requires. When people are involved in something that looks roughly like a coordination game, do enough of them choose behaviors that are "rational", so that the system evolves as the coordination theory predicts?

It may be hard to believe, but even after five decades of work on this subject, one can make the case that there's not much solid evidence that coordination game dynamics happen in the real world.

How can this be so? 
The core problem lies in the nature of social science as a research field. Social scientists study humanity in its groups. There are really only a few ways to do this.

1. You can write abstract theories, using words or mathematical symbols, and 'test' them against the intuition of the reader. Readers are all members of human societies. If the assumptions make sense to them, and the logic looks tight, the argument can be accepted. ${ }^{1}$

2. You can examine real human societies and compare across time periods or geographic boundaries. If two societies seem roughly similar in most respects, the remaining differences may relate causally to one another. ${ }^{2}$

3. You can conduct experiments with groups of people, assigning them at random to experimental and control groups. You expose the experimentals to some intervention, making that intervention the cause of any subsequent differences between the groups. ${ }^{3}$

4. You can immerse yourself in the society in question and use your deep knowledge to render subjective opinions about what is happening. ${ }^{4}$

All of these methods run into severe problems when asked to help us understand largescale social phenomena. Ethnography (\#4) suffers from a lack of a sufficiently broad perspective for the study of billion-person societies. Pure Theory (\#1) forces too much abstraction from the incredibly complex reality of a billion-person world. Comparison (\#2) cannot find two societies similar enough to allow observed differences to be traced to any set of causes capable of description or summary. Experiments (\#3) do not have enough participants. All of these methods can be used to hint at, point to, and suggest 
something about large-scale social entities, but none of them deals effectively with largescale social entities themselves.

Today, we study large-scale social entities only indirectly. There are no laboratories in which large-scale social entities can be directly examined. A social scientist, today, is like a marine biologist, an expert on salmon, who can examine anything in the world -- except salmon. He can theorize about salmon, he can watch movies of historical salmon that are now dead, he can conduct experiments with minnows and crabs. He can go out and swim upstream with salmon. But what he cannot do is bring some salmon into his lab, or put ID tags on them in the wild. He can only swim upstream with them and hope he's got an accurate theory about why they are doing that.

\section{Large Games: Supercolliders For Social Science}

In recent years, a new technology has emerged that represents the social science equivalent of a supercollider: an expensive machine that provides the only way to directly study certain interesting atomic phenomena. If you want to study the properties of atoms as they bang together, you must either do it indirectly, or build a big machine that can bang atoms together under controlled conditions. Similarly, if you want to study phenomena operating at the level of whole societies, such as large-scale coordination games, you must either do it indirectly, as above, or build a big machine that can host large-scale coordination games under controlled conditions. A new technology, which we can call "large games", do exactly that.

What is a large game? I propose it as a simple term for entities now known as MMORPGs, which stands for “Massively Multiplayer Online Roleplaying Games”. 
MMORPGs are a subset of the universe of synthetic worlds that the entertainment industry has started to build in great numbers. Synthetic worlds are online spaces that many people can use at once. If their use is channeled through a character that operates in a constructed social environment, complete with markets, governments, transportation, armies, and so on, we say that the synthetic world is actually a kind of game. Game here is understood in the sense of Malaby (2005), a designed choice environment with an uncertain outcome. And yet because this game occupies hundreds of hours of time, of hundreds of thousands of people, we should say that it is not an ordinary game, it is a large game.

The defining feature of a large game is that, because of its sheer size and complexity, it can be categorized as a genuine human society. In other words, the society we all lived in before the advent of synthetic worlds was itself a large game. True, it was the only large game, but these days it is no longer unique in that sense. The large game of Earth society now competes for my time with the large game of Norrath society, Norrath being the world of the videogame EverQuest, which at this writing hosts the attention of some 500,000 human minds on a daily basis. And so long as we focus on the core mechanics of a large game, there will be little in the way of significance difference between the behavior of individuals in one large game or another. In other words, core phenomena such as supply and demand, patronage, stigma, diplomacy, and yes: coordination, ought to operate similarly in all large games, wherever they are located. When teams of engineers from different companies tackle a design problem involving automotive emissions, the people are real, they are really engineers, the car is real, and the pattern of disjointed, competitive teamwork is real. When groups of warriors attack 
families of dragons in Norrath, the people are real, but their status as "warriors", arguably, is not. Nor are the dragons "real" in some sense. ${ }^{5}$ But the pattern of disjointed competitive teamwork is real, and no different in its essence, than the teamwork of the Earth engineers. Competitive, overlapping teamwork is just one of an uncountable number of core phenomena shared by all human societies, and, if a game gets big enough, these phenomena will appear in them with absolute fidelity.

We see the fidelity of large games to the large game of Earth society, for example, in the market forces that have been the subject of much of my earlier writing (Castronova, 2001). It is indisputable that supply and demand operate in synthetic worlds like EverQuest in exactly the same way they do in San Diego. If one has any doubt at all about this, the questions to ask are: did the invisible hand operate in ancient Athens? Does it function the same way in contemporary Nairobi? What about in Costa Rica, Beijing, or London? Of course. And, is it possible to imagine a more widely disparate set of cultures than these? No, not really. Of course the invisible hand operates in all these environments. And therefore, of course it operates the same way inside all large games. If it did not, what good would it be as a theory of human interaction? Any good theory ought to function in about the same way everywhere. ${ }^{6}$ Therefore any theory worth examining ought to function about the same way in all large games, online or offline. And there is no doubt in my mind that the core theories of economics all work the same way, whether the societies involved have collected themselves somewhere on Earth, or somewhere in cyberspace.

What's different about the online societies is that the large games being built out there, operate under controllable conditions. This is indeed a dramatically important 
difference, whose meaning for the future of social science research can hardly be overstated. Large games are social science supercolliders. They are synthetic worlds within which real societies accumulate. And while large games are certainly expensive to build, those who do build them manipulate many thousands of levers, buttons, and knobs that affect everything about the way the resulting society operates. Prices can be high or low, communication can be easy or hard, travel may be rapid or slow. There might be voting, or there might not be. It can rain, or shine. Builders can vary almost everything except human nature itself, making users mediate their interactions with one another through almost any kind of environment imaginable.

Given this level of control, an easy and yet breathtakingly powerful research strategy almost immediately leaps to mind: build several synthetic worlds in exactly the same way, except for some difference in a variable of interest. Put hooks in the data stream so that relevant metrics within the container societies can be observed. Attract people into the worlds, sit back, and watch what happens. With controlled construction of synthetic worlds, what we have in effect is a laboratory for large-scale social science research.

While a research method of controlled experiments in large games makes sense in theory, we do not know if it would be feasible or useful in practice. One might ask whether there is any evidence that large games offer enough of a controlled environment to make this approach really useful. For example, is it possible to introduce enough variance in the experimental effect to induce significant and observable behavioral changes? Perhaps behavior is so dominated by the surface-level 'game', the whacking of 
orcs and so on, that the things we care about (markets, politics, etc.) are mere sidelights that never change much, no matter what one does.

Thus we have two related questions to examine:

1. Do coordination effects really happen on a large scale in human society?

2. Are large games really amenable to controlled social experimentation?

The astute reader senses that the evidence I'll be submitting favors answers of "YES", and "YES."

\section{Evidence from Norrath}

In August 2001, I conducted a survey of EverQuest (EQ) players. The "Norrath Economic Survey,” or NES, became the basis for an initial paper on that economy’s core statistics (Castronova, 2001). One of the questions I asked, on which nothing has been reported thus far, involved the location of the player-to-player market. In EQ, at that time (there have since been revisions; see below), trade happened as follows. A seller would announce in the auction chat channel what items he had for sale. Because EQ’s terrain was split into dozens of separate zones, this announcement could only be 'heard' (that is, seen and read in the chat box) by those in the same zone as the seller. At the same time, everyone in that zone would hear it. A potential buyer would hear the proposed sale, and respond by private message to the seller. The two would then negotiate privately, striking a price. Then they would meet - that is, place their avatars in close proximity to one another - to enable to exchange functionality of the interface. One performed exchanges by clicking on another person's avatar, which opened a trade window. The buyer would place money in his side of the trade window, and the seller would place the item in his 
side. Both sides could examine the goods being proposed for exchange. When satisfied, buyer and seller would separately click an 'Agree' button. When both 'Agree' buttons had been clicked, the items would change possession. The purpose of my question about market location in the NES was simple: given this rather cumbersome means of marketmaking, were there certain zones that were preferred by all sellers and all buyers? Did the player market as a whole, have a specific geographic location?

The question of location bears interest because, under the conditions of trade in Norrath, EQ’s territory, the location of a player market looks like a coordination game. Consider the following unlogic: "The market is here because the market is here.” Once the market exists in location $\mathrm{X}$, it clearly behooves all players to travel to that location to conduct market activities. Buyers will come to X to shop because that's where the sellers are. If you want to hear all the offers, and take advantage of seller-vs-seller price competition, you should shop in zone X. Moreover, if you shop in X, doing the transfer will be quite easy, since both buyer and seller avatars are already in the same zone. And because the buyers go to zone $\mathrm{X}$ to buy, sellers will go to zone $\mathrm{X}$ to sell. That's where the buyers are. For reasons of both information exchange and transactions costs, it behooves all market participants to do their market activity in the same spot. And if everyone expects that other market participants will get together in zone $\mathrm{X}$, then everyone will indeed get together in zone $\mathrm{X}$, confirming the expectation and coronating zone $\mathrm{X}$ as the marketplace. And it is important to stress that nothing in this theory of market location is specific to online roleplaying games. It is equally amenable to the large game of Earth. If coordination has a role to play on Earth, it has one to play in Norrath. 
The question about market location was structured so as to reveal commonly-held expectations about where one should sell things. For reference, here is the question as it appeared in the survey:

“14.A. If your main character had a somewhat uncommon item that you needed to sell quickly at a fair price, where would you go to sell the item? What would be the best zone? Assume that you could get a teleport directly to that zone, so that travel time does not matter. Indicate a single zone here: ."

In essence, the question asked respondents for the preferred place to sell an item, independent of where their main character happened to be at the time of the survey. The answer was an open field; respondents could have put down anything.

It is interesting, therefore, that the responses came in the pattern shown in Table 1: Server by server, EQ players agree -- to a statistically extreme degree - where the main market is.

\section{[Table 1 here]}

It is unusual in any distribution of human responses and behaviors to find commonalities above 65 percent. The populations of EQ servers usually ran to 10,000 players, of which some 2,000 - 3,000 would be online at any one time. ${ }^{7}$ When more than 85 percent of such a population says that they share some feature, that feature is no longer just 'frequent' in that population; from an outside perspective, we should think of it as 'near universal.' That feature certainly dominates culture and expectations. Thus, that fact that a large majority of EQ's server populations have 85-95 percent agreement on the location of the market - in response to an open-ended question, no less - is strong evidence that the zones indicated represent a powerful shared expectation of these populations. “The market is there.” Such statistics bear up my own impression when wandering the lands of 
Norrath: on every server, everyone knew where the market was. It was a firm and fixed part of the culturo/economic landscape. Where the statistics seem to offer less certainty about market location, there are some clear explanations. In the case of Lanys T’Vyl (36 percent agreement) and Vazaelle (65 percent), the response rate was uncharacteristically low (14 and 57 observations, respectively). And in the case of Tallon Zek and Vallon Zek (69 percent), we have here the hard-core player-vs-player servers. It is a prediction of market theory that conditions of war impede efficient market formation. From a coordination game perspective, if coordination leads to vulnerability to attack, as it would on these servers, this danger lessens the incentive to coordinate. Better to throw an item away than earn death by trying to sell it. As a result, the forces directing market activity into a single location are lessened; the marketplace does not form as strongly as it does under conditions of peace. This also is consistent with the general idea of market location as a coordination game. Thus whether one looks at the exceptions, or the consistent cases, the rule is quite clear: in Norrath, market location looks like a coordination game.

Now, in what sense is this kind of evidence more persuasive than, say, historical evidence from Earth? For we can find many examples of markets being located on Earth in certain places. America's principal stock exchange is located in New York, and has been for decades. Chicago is the location of America's primary commodity market. The television industry is located in Los Angeles. The question is, does this kind of evidence identify coordination effects as the source of the staying power of these market locations? Having a market in a single place is certainly consistent with coordination game theory, but it's consistent with many other theories, too. One could tell stories. LA has TV because LA had movies, and LA had movies because it had sun. But San Diego has sun, 
too. However, San Diego did not have the Southern Pacific Railroad, and that is because LA's business leaders convinced SP to make their port, and not the (superior) Port of San Diego, the railroad's western terminus. Was this because LA was closer to San Francisco? If so, then LA's status as the headquarters of television was driven by the forces of economic history, not coordination effects per se. Or was it an accident, a random choice in a coordination game being played by lots of folks in the late $19^{\text {th }}$ century, among them the directors of Southern Pacific? In the latter case, if history were to repeat itself, coordination effects alone would allow a TV industry to emerge in La Jolla instead of Burbank. Similarly, if we merely note that for months and months, people on the Bertoxxulous server have been doing their market activity in East Commons, we have added very little to what we know about coordination effects.

Where EQ offers some new information on coordination is in the conditions under which its marketplaces were founded: in EQ, each server is an exact replica of the others, and so the EQ servers as a whole represent 40 replays of the same history. In other words, on Earth we have one experimental world, the Earth itself. In Norrath, we have 40 Earths, each exactly the same except for a few differences involving age, the ruleset, and the uncontrolled sorting of populations to servers. Thus when we observe a pattern of variation by server, we are observing the grand and exhiliarating WHAT IF that has been dreamed of by generations of social observers: What if we re-ran the history of television? Would it end up in Burbank or La Jolla? ${ }^{8}$ With 40 Norraths, exactly that kind of judgment is possible; we can do more than tell tales based on a single history, we can observe multiple, parallel histories and weave an argument based on a firm understanding of underlying probabilities. And this is only possible because EQ is not just a large game, 
it is a large game occurring under controlled circumstances of parallism. Controlled to emerge in 40 replicated incarnations, the worlds of Norrath offer unprecedented new information about social behavior.

The specific information offered about coordination is quite helpful and clear, in fact: The evidence from Norrath suggests strongly that coordination plays a very strong role in market location. This is because we can view the evidence from Norrath as the outcome of an experiment. The experiment is this: Open 40 versions of the same physical world and attract individuals into them. Observe where markets are located. If market location has the features of a coordination game, as illustrated in Diagram 1 above, it should be the case that

- The market coalesces at a single location, AND

- The market does not always coalesce in the same place

The first prediction is consistent with the observed history of our offline large game, the Earth economy. LA is a single place, and the TV industry is there, not elsewhere. The first prediction also is confirmed in our Norrath large games: on each server, the market has a single location.

The second prediction is where EQ provides a unique perspective, allowing us to identify the distinct role of coordination effects. For if market location is about coordination to some degree, then there is the possibility of multiple, different outcomes. Indeed, it is possible for different market locations to become entrenched with an equal degree of force, even though the locations are better for some people and worse for others. And indeed, that is the pattern we observe in Norrath. 
Returning to Table 1: On most servers, 27 to be exact, the market is located in East Commons (EC). On nine servers, the market is in Greater Faydark (GF), and on the remaining four it is in North Freeport (NF). We who know EQ well understand the various advantages and disadvantages of these locations as marketplaces. ${ }^{9}$ Arguably, EC had the most advantages, but in the absence of parallel experiments, we would not know whether the advantages of EC were such that coordination effects could not displace EC as the marketplace. However, since we do have parallel experiments, we can conclude with certainty that mere coordination was sufficient, in 13 of 40 cases, to keep the market elsewhere. Thus, whatever the forces were that made EC the predominant marketplace location, they were not stronger than coordination effects. On 13 servers, some accident of history dictated that the marketplace would start up in Faydark or Freeport, and once it did, coordination effects ensured that it would stay there, and not move to EC. And this happened even though, for example, evil characters had a much harder time participating in markets in Freeport than in East Commons. It happened even though the Faydark is located well to the East in Norrath's geography, placing it considerably off-center in most travel routes. These two sites retained their status as the marketplace because, well, they were the marketplace. Coordination alone made their status robust. Thus, the evidence quite clearly supports the idea that coordination is itself a powerful macro-social force. ${ }^{10}$

The data can be parsed for more results that support the basic idea. For example, it seems as though EC was comparatively more predominant in the early stages of the game. Almost all of the servers founded in or before March, 1999, the game’s launch date, have markets in the EC zone (88 percent). The frequency of EC falls off considerably after that date (54 percent). Is it possible that changes to the game altered 
the relative advantages? Later evidence on this score is fairly persuasive: about a year after the time of the NES, the designers implemented a zone called 'The Bazaar' and made it easily accessible from almost anywhere in the world. Moreover, in this zone money had no weight, banks were readily available, and good and evil characters were treated equally by the guards. Finally, in this zone players were allowed to automate their selling, setting up their characters as merchant robots who wares could be search through an eBay-style interface. No more hawking of goods and one-on-one negotiations, in other words. When the Bazaar was implemented, it was so obviously a better place to buy and sell that all of the old market zones immediately were emptied of all auctioning activity. At some level, market function must dominate coordination effects. On the other hand, the opening of the Bazaar was not a secret - the designers acted very prominently as a Third Party, a voice sending signals to the entire population, telling them all 'as of tomorrow, the market will be here.' Coordination theory predicts in that case that the market may well move, if everyone's mind can be changed at once. And in this case, it did, on every server. So perhaps the slight erosion in the dominance of EC early on has something to do with transactions costs, travel, or information.

On another dimension, the history of the game as a whole offers further confirmation of the role of coordination effects. As EQ grew, the designers created new servers. Sometimes they simply opened up new worlds for new characters only. Other times, they let players with advanced characters on older, crowded servers move those characters to the new server. The latter was called a 'split'. Thus, on March 1, 2000, the server Fennin Ro was ‘split’ into Fennin Ro and Druzzil Ro; Druzzil was a new server, just opened, and characters on Fennin could choose which server to play on. Meanwhile, 
since many servers were crowded, players from other servers would start new, level-1 characters there too. A server split, in other words, created quite a mishmash of population on the new server, yet with a hefty chunk of advanced characters from the old server. If forces other than coordination - including, this time, something unique about the player base of the servers - then there ought to be some dependence in market location through these server splits. If not, if market location is driven mostly by random factors that then get reinforced by coordination effects, then servers that are 'born' out of old servers should be unlikely to simply inherit the old server's market location. Rather, each new server would be like a new experiment; the new population, whether transferring from the old server or starting anew, would replay the core experiment of market location and come to its own historical outcome, choosing its own location from among the foci of East Commons, Greater Faydark, and North Freeport.

Table 2 summarizes the seven server splits and their outcomes. There are seven splits, all from the very first servers founded in March 1999. All of those servers had East Commons as the marketplace. Yet after the split, only three of seven retained EC as the marketplace. Three of the new servers chose Greater Faydark, while one chose North Freeport. If some sort of direct force were dictating market location - specifically the force of remembered history, resident in the minds of players moving from an EC server to a new one - then every one of these servers should have had its marketplace in EC. Yet Faydark was just as likely as the Commons in this small sample. Thus even though population is not controlled here, the evidence still suggests that coordination effects are a strong force, relative to other considerations, in the placement of markets. 
One last piece of evidence: The designers apparently intended for markets to occur, and it appears they had locations in mind. Every city had some sort of market area, spacious, safe, with nearby banking and NPC merchants to facilitate trade. At times, these were even placed directly on trade routes, such as the tent merchants near the Port of Qeynos. However, with the exception of North Freeport, it appears that actual human trade did not occur with any frequency in the places designed for it. ${ }^{11}$ In the vast majority of cases, all of the constructed markets, on all servers, were as quiet as tombs, almost all the time. This has two implications. First, merely designating something as a market is insufficient to force markets to locate there; while the voice of the third party can have an effect when choosing among equally prominent foci, it cannot make an entire population coordinate on a bad outcome. Things other than Voice, such as transportation routes and local services, are more important. Secondly, this outcome makes EQ safe as an experimental testbed for a market location study. If the designers were attempting to induce some kind of market location outcome, they failed utterly. The location of the markets was an emergent property of the player base in its interaction with the world, unaffected by designer intent. It was as natural an experiment as one could imagine.

In sum: the 40 servers of EverQuest observed in August 2001 constitute a reliable natural experiment on coordination effects in market location. The evidence indicates that the theory of coordination games does indeed operate on a large-scale level in human societies. Both the power and the fragility of coordination were apparent. If you were an evil character, but lived on a Freeport server, the value of the market to you was lessened. Yet you still had to do your buying and selling in Freeport, despite the hassle this apparently caused. The market was where it was; no one could easily change that; and its 
location had coercive power on all the players. At the same time, the fragility of coordination was evident as well, as new split servers seemed equally likely to move to a new market location, as to retain the location of the parent server. In terms of both the breadth and depth of the theory, the markets of EverQuest offer rich evidence of coordination's existence, and its force.

\section{Evidence from Camelot}

Mythic Entertainment's Dark Age of Camelot (DAoC) has received less scholarly attention than EverQuest, but for the purposes of this paper they are equivalent: both can be construed as large games with replication. As large games, they host macro-social effects no different from those encountered here in the outer world. As replicated games, they offer insights with the quality of controlled experiments. Like EQ, DAoC's serversocieties might tell us something about coordination effects. If so, such evidence lessens any doubts we might have that EQ is somehow special in this regard. That is important. The argument here is that the value of large games as research tools lies in their plumbing, in their structure. It should be possible to switch from a Tolkienesque world of elves and rings to an Arthurian world of paladins and grails, and still obtain valuable pseudo-experimental insights. ${ }^{12}$

The evidence that Camelot brings to bear is best illustrated descriptively rather than through data; it is based on a number of points that were obvious to anyone spending time there.

The point of gameplay in DAoC was to engage players from other realms in $\mathrm{PvP}$ (player-vs-player) combat. Designers created three realms and then crafted three 
battleground zones, one belonging to each realm. Within each realm's zone were several strongholds and castles, the largest of which contained precious relics of the realm. The power of each realm's players was in part determined by how many of these relics their realm owned. Thus, players were incented to enter the battleground zones of enemy realms, attack their castles, and try to take relics. At the same time, of course, each realm had to defend its own relics.

The strategic situation, from a general's-eye view, was an interactive game with no obvious outcome, much like Rock-Paper-Scissors ${ }^{13}$ : Three zones, A-B-C, three players 1-2-3. If Player 1 sends his army to zone A, and players 2 and 3 do not, then Player 1 gets the relics in A (or keeps his relics from the others). If two or more armies met, there would be a battle, with the winner getting relics. In any round of play, there are multiple possibilities: no conflict, 1 on 1 conflict, 2 on 1 conflict, or 1 on 1 on 1 conflict. On the surface, this game looks to provide the same kind of fluidity of outcomes that Rock-Paper-Scissors does, except that, as with poker, knowing the 'tells' of the other generals could be extremely helpful. Assuming a reasonably open promotion system within the player-bases of the three realms, one could guess that the three leaders would be pretty good generals, and not have obvious tells. Thus one would expect balance among the realms, and changeable, exciting combat going on each night in the three battleground zones.

However, as Camelot aged it emerged that most players spent most of their time in only one of the battleground zones, Emain Macha. It was not entirely uncommon to encounter organized combat in the other zones, but raids on relic castles were fairly rare. And the fighting in Emain was rarely organized. Rather, the forces of Albion and 
Midgard -- technically, invaders - would mob together at their respective invasion points, which were quite close, and the forces of Hibernia - technically, defenders - would amble the long distance from their homeland out to this frontier. Thus mobbed in proximity, the players would engage in more or less endless mob-like fighting - a thrust here, a retreat there, a panic, a few foes vanquished; run back to safety and try to repeat. Though this was ‘victory', no relics changed hands. The Emain 'zerg', as it was called, was considered by many players to be a letdown in terms of gameplay, but nonetheless it was the primary PvP pattern produced by Camelot’s design.

A number of factors explain the deviation of player behavior from designer intent, and coordination game theory has a dominant role. Let's begin with some critical details. First, Emain had wide green fields and gentle slopes, in contrast to the other two battlegrounds, which were mountainous and densely forested. (One player described Emain as "a big golf course”.) Second, the rewards of relic-taking were shared among the entire population of a realm, whereas rewards from killing foes in individual combat, called "realm points", accrued to the individual player. Third, the game offered no explicit or implicit authority structure among the players, other than a system of selforganizing and voluntary player clubs ("guilds"). Fourth, there were no supply lines, no sense of the 'front' and 'rear' or a fighting force, nor any way for one body of troops to impede the movements of an enemy force - one player could simply run through another, as though that player did not exist. Combined, these features turned the combat game of Camelot into a coordination game, with extraordinarily powerful incentives built in to play that game one and only one way. 
To begin at the end: with no authority, no supply, and no sense of military space, there was no reason in Camelot for armies to even exist. No one could actually give orders and expect them to be followed; no tools existed whereby this kind of authority could emerge. On the contrary, the tools effectively prevented the emergence of authority, by making sure than anyone could leave any group, guild, or military formation at any time and face no worse consequence than the annoyance of their erstwhile comrades-in-arms. Meanwhile, the absence of contact-detection, supply, etc., made sure that no one had a self-interested incentive to stick together or hold a particular formation or piece of ground. This almost forced all fighting formations to be loosely-affiliated mobs of players. This then was reinforced by the incentive scheme. Public choice economics (Buchanan and Tullock, 1962) long ago clarified the simple fact that rewards shared by a collectivity are dramatically less motivating than rewards one obtains for oneself. If individual rewards are obtained for combat pure and simple, while relic raids give rewards to the entire realm, it is obvious that most players will spend their time seeking out combat for combat's sake alone, and leave relic-taking to special circumstance. Thus we have loosely-affiliated mobs of players, all of whom seek to accomplish nothing more than combat with one another. And lest this seem to be a harsh critique of the designers, it was obvious that the players found this kind of fighting extremely fun. It is not fun to march about for hours while the generals maneuver, only to be ordered at the moment of battle to stay back and guard the baggage. Not fun. Much more fun to engage in endless random melee that has no real purpose consequence for anyone. Because it was flexible, allowing both relic-raiding and zergwar, Camelot's 
design should be judged a success. Nonetheless, it seems that the predominance of zerging was a surprise to everyone.

Given these incentives to zerging, however, coordination then plays a huge role in making it happen as players want. Here we have mobs of players who want nothing more than to attack one another, a lot, and so rack up thousands and thousands of realm points. To do that, the players of the three realms do best to identify one spot for fighting, and go meet one another there, always. The worst disaster would be to have confusion about the location of the battlefield. What if the Britons went to the Viking-home of Midgard, the Vikings to the Celt-home of Hibernia, and the Celts to the Britain-home of Albion? No zerg, and no points. It behooves all players, as with the market location example, to settle on one spot. And in this respect, the lush, rolling fields of Emain were evidently preferable. Enemies could be easily spotted and assaulted. Anyone looking for a mob of fellows could easily find them. Meanwhile, rogues and other invisible characters, who were generally considered impossible to beat if they got close while still hidden, had fewer places to hide. In fact, the only argument against Emain would have been made by the Hibernians, who had to travel much farther to get to the fighting areas than the other two realms. Yet the advantages of the space, and its easy affordance for zerg combat, overcame the natural resistance of Hibernia. Thus, on each of Camelot's 20+ servers, most combat occurred in Emain Macha, because of the combination of player incentives and a corresponding powerful return to broad social coordination. ${ }^{14}$

Here again we have evidence of the power of coordination effects, and again the evidence is richer because of the quasi-experimental nature of the large game in which these effects were observed. If coordination effects were not powerful, then the 
Hibernians should have been able to force changes from time to time in the location of the zerging warfare, on at least some servers. They were not. Rather, Hibernia was everywhere forced to accept the benefits of coordination with Albion and Midgard, despite the cost of doing so in Emain Macha. And later developments suggest that the coordination effects were also fragile. In a later change in the geography of the zones, the Hibernian battleground was no longer made into a flatter, more-open version of the others, and the concentration of warfare there ceased. ${ }^{15}$

Thus, here we have a second example of a large game serving as a natural experiment on the subject of large-scale social coordination. If a designer establishes 20+ versions of the same world and imposes on each version a similar set of incentives to mob warfare, and then creates one zone where mob warfare is particularly easy to accomplish, she has built an experiment where 20+ human societies are playing a coordination game, and one of the game's focal points has a higher payoff than the others. Theory predicts that each society should gravitate to the high-payoff focal point, and that is, in fact, what has happened. This is a second experimental confirmation of the existence of coordination effects at the macro-social level, made possible only by the uniquely (though naturally, through no intent of the designers) controlled conditions presented by a large game.

\section{Conclusion}

This paper set out to make two points:

1. Coordination effects really do happen in large human societies.

2. A fine way, and maybe the best way, to find evidence of them is in large games. 
Support for these points relied on a common intuition about the nature of human society: it runs on some kind of underlying structure, a structure that operates in roughly the same way regardless of where the society is located in space or time. The structure of social interaction does not predict all things social, but it does predict some of them. Thus, supply and demand and the invisible hand have something to say about the prices of goods, no matter where those goods are or what other things are used to price them. I've argued that coordination effects are similarly a common feature of human society, that under certain circumstances we find ourselves in a huge game where there are, on the one hand, powerful incentives to conform to the expectations of others, while on the other hand, it is obvious that merely by changing our expectations collectively we could cause our behavior to conform to some other norm. And if coordination and conformity operate at some abstract level, they should be observable in all kinds of societies, including the societies contained in large games. Large games are large enough, conceptually and technologically as well as in terms of raw population and hours of use, to be considered genuine human societies in their own right. Unlike most human society, however, the societies of large games can be grown, as it were, under carefully-controlled circumstances. And one circumstance that has been unintentionally built by the designers of several large games is replication: a single large game with a single structure is built over and over again, in exactly the same way. As such, the set of replicated worlds represents multiple trials of an experiment. And in these trials, we see things that no amount of historical, theoretical, or deep-knowledge research can show us: we can see the probability distribution of a human society, viewing its features not as from a single outcome, but from the whole range of things that might have been but were not. The 
opportunity to see large-scale social outcomes from a truly probabilistic, experimental perspective has never before existed in the long history of social thinking. It is an advance of incredible power and value.

I argued that large games, valuable though they might be, are also expensive, and thus represent a social science version of large-scale physics tools like supercolliders. To demonstrate the value, I explored natural experiments provided by two social science supercolliders that already exist (though unwitting in their role as tools of research): EverQuest, and Dark Age of Camelot. These two behemoths of gaming, each with more than 200,000 active subscribers, have in pursuit of commercial objectives crafted controlled circumstances for bashing atoms of social science theory into one another, crudely, and without reference to any research hypothesis whatsoever. Yet we can observe the trace patterns left by these collisions, and they tell a reliable story: coordination effects really do occur at the level of all society. When the incentives are right, a whole society of real people act as coordination theory predicts. This result is based on direct observation of dozens of comparable, parallel societies. It is important to contrast this directly with the methods currently available to social scientists. To make this absolutely clear:

- The results are not based on a study of coordination among 12-16 undergraduate students in a lab, playing abstract games for a few dollars.

- The results are not based on an analysis of coordination by some groups in France as compared to some groups in Germany, or in France in an earlier age. 
- The results are not based on a pure theory of what coordination might be, without any reference at all to actual human behavior.

- The results are not based on the researcher's impression after having spent 12 months living with a small subset of one of the populations.

- The results are based on the direct observation of parallel, replicated societies in which coordination behaviors were possible but not induced.

It should be apparent from the tone that I think the latter mode of study is at least as reliable, and quite possibly more so in some respects, than those that precede it. While the evidence from experimental large games does suggest that coordination effects do exist at the macro-social level, I would argue that there is a bigger finding here. The big news is not that coordination effects exist, but that large games can find them. That being the case, one might predict that a new large-games focus in social science research methods may be about to emerge. 
Table 1. Distribution of Market Locations by Server

\begin{tabular}{|c|c|c|c|c|c|c|c|c|}
\hline ID & Name & $\begin{array}{l}\text { Launch } \\
\text { Date }\end{array}$ & $\begin{array}{l}\text { Split } \\
\text { to }\end{array}$ & $\begin{array}{l}\text { Split } \\
\text { from }\end{array}$ & $\begin{array}{l}\text { Unqiue } \\
\text { Features }\end{array}$ & $\begin{array}{l}\text { Trade } \\
\text { Zone }\end{array}$ & TZ Freq & $\mathrm{N}$ \\
\hline 01 & Bertoxxulous & 01/04/99 & 34 & & & EC & 84.78 & 92 \\
\hline 02 & Fennin Ro & 02/17/99 & 27 & & & EC & 89.60 & 125 \\
\hline 03 & Rallos Zek & 02/17/99 & & & PvP & EC & 89.32 & 103 \\
\hline 04 & Rathe & 02/17/99 & 39 & & & EC & 92.04 & 113 \\
\hline 05 & Tarew Marr & 02/17/99 & 37 & & & EC & 93.46 & 107 \\
\hline 06 & Xegony & 02/17/99 & & & & NF & 92.31 & 91 \\
\hline 07 & Cazic Thule & 03/03/99 & 38 & & & EC & 89.61 & 77 \\
\hline 08 & E'ci & 03/03/99 & 39 & & & EC & 90.00 & 80 \\
\hline 09 & Karana & 03/03/99 & 38,34 & & Europe & EC & 95.96 & 99 \\
\hline 10 & Mithaniel Marr & 03/03/99 & 36 & & & EC & 91.74 & 109 \\
\hline 11 & Povar & 03/03/99 & 37 & & & EC & 83.33 & 96 \\
\hline 12 & Solusek Ro & 03/03/99 & 38 & & & EC & 89.04 & 73 \\
\hline 13 & Veeshan & 03/17/99 & 30 & & & EC & 90.77 & 65 \\
\hline 14 & Bristlebane & 03/26/99 & 30 & & & EC & 87.63 & 97 \\
\hline 15 & Innoruuk & 03/26/99 & & & & NF & 88.30 & 94 \\
\hline 16 & Tunare & 03/30/99 & 36 & & & EC & 92.05 & 88 \\
\hline 17 & Rodcet Nife & 04/28/99 & & & & GF & 95.89 & 73 \\
\hline 18 & Prexus & 06/07/99 & & & & EC & 86.27 & 102 \\
\hline 19 & Brell Serillis & 07/21/99 & & & & EC & 91.54 & 130 \\
\hline 20 & Tallon Zek & 07/30/99 & & & PvP & GF & 68.89 & 45 \\
\hline 21 & Vallon Zek & 08/02/99 & & & PvP & EC & 69.05 & 84 \\
\hline 22 & Tribunal & 08/17/99 & & & & NF & 90.12 & 81 \\
\hline 23 & Nameless & $10 / 14 / 99$ & & & & GF & 81.71 & 82 \\
\hline 24 & Lanys T'vyl & $12 / 21 / 99$ & & & & GF & 35.71 & 14 \\
\hline 25 & Vazaelle & $12 / 22 / 99$ & & & & GF & 64.91 & 57 \\
\hline 26 & Luclin & 01/23/00 & & & & EC & 85.92 & 71 \\
\hline 27 & Druzzil Ro & 03/01/00 & & 2 & & EC & 91.67 & 84 \\
\hline 28 & Morelle-Thule & 04/18/00 & & & & EC & 90.32 & 93 \\
\hline 29 & Torvonnilous & 04/18/00 & & & & EC & 85.45 & 55 \\
\hline 30 & Saryrn & $04 / 28 / 00$ & & 14,13 & & EC & 93.33 & 105 \\
\hline 31 & Seventh Hammer & 04/28/00 & & & & EC & 85.26 & 95 \\
\hline 32 & Erollisi Marr & 05/06/00 & & & & EC & 90.16 & 61 \\
\hline 33 & Quellious & $06 / 24 / 00$ & & & & EC & 83.61 & 61 \\
\hline 34 & Terris-Thule & 07/19/00 & & 09,01 & & GF & 91.58 & 95 \\
\hline 35 & Tholuxe Paells & 09/28/00 & & & & GF & 68.75 & 64 \\
\hline 36 & Drinal & $10 / 03 / 00$ & & 10,16 & & EC & 88.37 & 86 \\
\hline 37 & Xev & $11 / 21 / 00$ & & 5,11 & & NF & 91.43 & 70 \\
\hline 38 & Ayonae Ro & $12 / 19 / 00$ & & $07,09,12$ & Europe & GF & 94.00 & 100 \\
\hline 39 & Zebuxoruk & 03/21/01 & & 08,04 & & GF & 80.00 & 85 \\
\hline 40 & Sullon Zek & 07/02/01 & & & PvP & EC & 93.15 & 73 \\
\hline
\end{tabular}

Source: NES 2001. Splits refer to the practice of founding new servers by allowing players from certain older, crowded servers to move to the new server. Example: On March 1, 2000, the server Druzzil Ro was founded, and all players from Fennin Ro were allowed to transfer characters there. Trade Zone: EC= East Commons, GF = Greater Faydark, NF = North Freeport. TZ Freq: Percent indicating the given zone. N: Number of respondents from that server. 
Table 2. Server Splits and Market Location

\begin{tabular}{|c|c|c|c|c|}
\hline Date & Old Servers & $\begin{array}{c}\text { Old Server } \\
\text { Market Location }\end{array}$ & New Server & $\begin{array}{c}\text { New Server } \\
\text { Market Location }\end{array}$ \\
\hline $3 / 1 / 00$ & Fennin Ro & EC & Druzzil Ro & EC \\
\hline \multirow{2}{*}{$4 / 28 / 00$} & Veeshan & EC & \multirow{2}{*}{ Saryrn } & \multirow{2}{*}{ EC } \\
\hline & Bristlebane & EC & & \\
\hline \multirow{2}{*}{$7 / 19 / 00$} & Karana & EC & \multirow{2}{*}{ Terris-Thule } & \multirow{2}{*}{ GF } \\
\hline & Bertoxxulous & EC & & \\
\hline \multirow{2}{*}{ 10/3/00 } & Mithaniel Marr & $\mathrm{EC}$ & \multirow{2}{*}{ Drinal } & \multirow{2}{*}{ EC } \\
\hline & Tunare & EC & & \\
\hline \multirow{2}{*}{$11 / 21 / 00$} & Tarew Marr & $\mathrm{EC}$ & \multirow{2}{*}{ Xev } & \multirow{2}{*}{ NF } \\
\hline & Povar & EC & & \\
\hline \multirow{3}{*}{$12 / 19 / 00$} & Cazic Thule & EC & \multirow{3}{*}{ Ayonae Ro } & \multirow{3}{*}{ GF } \\
\hline & Karana & $\overline{E C}$ & & \\
\hline & Solusek Ro & EC & & \\
\hline \multirow{2}{*}{ 3/21/01 } & Rathe & EC & \multirow{2}{*}{ Zebuxoruk } & \multirow{2}{*}{ GF } \\
\hline & E'ci & EC & & \\
\hline
\end{tabular}

Source: NES 2001 and published information from EverQuest about server splits. 


\section{References}

Buchanan, James M. and Gordon Tullock. 1962. The Calculus of Consent: Logical Foundations of Constitutional Democracy. Ann Arbor: University of Michigan.

Castronova, Edward. 2001. "Virtual Worlds: A First-Hand Account of Market and Society on the Cyberian Frontier.” CESifo Working Paper 618, December.

Dixit, A. and Skeath, S. 1999. Games of Strategy. New York: W.W. Norton \& Company. Fudenberg, D. and J. Tirole.1991. Game Theory. Cambridge, MA: MIT Press.

Greif , Avner. 1993. "Contract Enforceability and Economic Institutions in Early Trade: The Maghribi Traders' Coalition." American Economic Review, 83(3), June, pp. 525-48. Malaby, Thomas (2005), “Ethical Code: Modernity and the Game Concept in Computer Game Design,” working paper.

Reeves, B. and C. Nass. 1996. The Media Equation: How People Treat Computers, Televisions and New Media Like Real People and Places. Cambridge: Cambridge University Press.

Schelling, T. C. 1960. The Strategy of Conflict. Harvard University Press, Cambridge, MA. 


\section{Notes}

${ }^{1}$ There is a vast literature of purely theoretical treatments of coordination games. Interested readers should
start with basic textbooks, such as Fudenberg and Tirole (1991) or Dixit and Skeath (1999).
${ }^{2}$ To my knowledge, there are no comparative studies that invoke coordination games as a theory for
explaining differences in outcomes. The economic historian Avner Greif, however, has used coordination
theory to study trade patterns in the Mediterranean (Greif, 1993).
${ }^{3}$ There is a large literature on experimental games. Again, the interested reader would be directed to the
leading texts in game theory (see note 1).
${ }^{4}$ I know of no ethnographic studies that invoke coordination game theory to explain observed behavior.
${ }^{5}$ Recent research in psychology disputes assertions that the things in Norrath are "not real". A significant
body of research indicates that the mind treats virtual things largely as if they are real (Reeves and Nass,
1996). The labels of "real world" and "fantasy world" are apparently mere conveniences for most game
players - they just identify where something happened, not whether it has any existence or meaning.
${ }^{6}$ I am not saying that a theory has to make the same predictions everywhere, or that all societies are the
same. On the contrary - a good theory allows for and explains social diversity, just as the theory of supply
and demand explains why the price of rice is higher in Moscow than in Bangkok. Moscow and Bangkok
are very different places, but through the theory we can see why they are different, and what effect their
differentness has on things we can observe, like prices. My point is only that a good theory has to work
with nuts and bolts that have broad relevance.
${ }^{7}$ For those not familiar with the structure of MMORPGs: technology constrains the maximum number of
players that can share a given world at the same time. At the time of this writing, the constraint is about
three or four thousand players. Game companies know that if 10,000 users have an account with access to a space, only about 3,000 or so will be online at any one time. Therefore, one scales a game like EQ on a server by server basis: the first 10,000 subscriptions go on Server 1. If more than 10,000 people sign up, Server 2 is opened. If more than 20,000 sign up, Server 3 is opened. And so on. Thus EQ's 400,000 players were hosted on 40 servers, 10,000 players each. The critical point is that each of these servers is providing exactly the same game to all the players. The terrain is the same, the enemies are the same, the quests are the same, the transportation is the same. At most, there might be slight variations in the rules (as when players are allowed to use their combat abilities against one another: player-vs-player, or 'PVP', which is not the norm). Thus, each server is essentially a replicate of server 1: another in a long line of large-scale, societal Petri dishes.

${ }^{8}$ To perhaps better expressed how poignant such questions have been, consider this: What if we re-ran German history 40 times? Would Hitler have advanced to power in every incarnation of the Weimar Republic? In most of them? In only a few? Was Hitlerism a rare and tragic mishap for the world? Was it avoidable? Unlikely? Or pre-determined, fated, inevitable? It is hard to overstate how valuable that information would be, from the perspective of emotions no less than policy, to hundreds of millions of people living today. If we had 40 Weimar Republics, we could make a judgment about those questions. ${ }^{9}$ The reasoning behind each of the three marketplaces is as follows. East Commons: The market there took place in 'the EC Tunnel', a tunnel that allowed players to move from the East Commons zone to the North Ro zone. The tunnel offered many advantages as a marketplace. First, here good and evil characters could freely interact, whereas in most cities the one or the other would be chased and killed by guards. Second, East Commons itself was a crossroads for both types. Good characters crossed through here when passing from the human cities of Antonica, in the west, to the elven lands of Faydwer in the east. Evil characters came through East Commons when traveling between the ogre and troll lands of South Antonica and the Dark Elf empire of Neriak in North Antonica. Third, the EC Tunnel was spacious and had clear landmarks. On the walls were a series of torches, and merchants would announce location by saying "see me at the second torch." Finally, the EC tunnel had no monsters at all, and was completely safe. Greater Faydark: though located well to the east, GF was home to two of the most popular races, the wood elves and high elves. Moreover, two other races, gnomes and dwarves, would cross through GF to get to adventuring areas. GF is a dark place with fairly low-level monsters and lots of open spaces, meaning that good and evil characters could freely mix and mingle. It was home to both a druid ring and a wizard spire, which at that time meant, in effect, 'airport': at those sites, druids and wizards respectively could transport players to and from far-flung locations. Finally, unlike EC, GF had convenient banking services. North Freeport: NF was a zone inside the city of Freeport, which was adjacent to East Commons. As such, it 
benefited from a similar crossroads effect and, being a city zone, there were no monsters at all. Like GF, NF had a convenient bank. Unlike EC and GF, however, NF was not congenial to evil characters; evil characters had to implement workarounds to do their marketing in that zone. On the other hand, of the three candidate zones, NF is the only one that looks like a marketplace, with stalls and NPC merchants scattered about.

${ }^{10}$ With no small amount of trepidation, I would venture to claim that this is the first time in human history that a distinct macro-social phenomenon has actually been verified experimentally. Nearly-parallel societies have simply never existed until now.

${ }^{11}$ The elf city of Kelethin was in the Greater Faydark zone, so one could technically say that the GF market was "in" Kelethin. But practically speaking, it was not. Kelethin was a city in the trees, and no one went up there to do their trading.

${ }^{12}$ There are actually a number of concrete differences between these large games at the level of plumbing as well. Three worth mentioning: EQ allows PvP only as an exception, whereas in Camelot it is the rule. In EQ, all players interact with one another, whereas in Camelot the player base is split into three factions that have no technical means for communicating. Finally, in Camelot the level of market activity was lower than in EQ, mostly because fewer goods were sensibly tradable.

${ }^{13}$ Formally speaking, the assertion is that, like Rock-Paper-Scissors, the game does not have a pure strategy equilibrium.

${ }^{14}$ Here I do not have survey data to back up the assertion that Emain was a zerg combat locale on all of Camelot's servers. Yet I think it would be undisputed by any open-minded visitor to Camelot that Emain was known throughout the lands, in a nearly-universal opinion, to be the location of mindless zerg fighting, every night, on every server.

${ }^{15}$ Admittedly, the evidence for coordination effects per se is weaker with Camelot than with EverQuest. EQ's server splits clearly show that coordination was a power in its own right, that characteristics of the markets did not always dictate where the markets were. In Camelot, the characteristics of Emain seemed to dominate coordination effects; I know of no examples where a server saw most of its zerg action in another zone. As argued in the text, this is the case of a coordination game with an equilibrium that is so dominant in its payoffs that it is assured of being selected by virtually any society. As such, it provides weaker evidence of coordination per se than a more varied outcome would. On the other hand, it is still telling that one can establish 20 parallel societies and see the same emergent coordination in each; though weaker than in the EQ case, it is still strong evidence for coordination. 


\section{CESifo Working Paper Series}

(for full list see www.cesifo-group.de)

1557 Piotr Wdowinski, Financial Markets and Economic Growth in Poland: Simulations with an Econometric Model, October 2005

1558 Peter Egger, Mario Larch, Michael Pfaffermayr and Janette Walde, Small Sample Properties of Maximum Likelihood Versus Generalized Method of Moments Based Tests for Spatially Autocorrelated Errors, October 2005

1559 Marie-Laure Breuillé and Robert J. Gary-Bobo, Sharing Budgetary Austerity under Free Mobility and Asymmetric Information: An Optimal Regulation Approach to Fiscal Federalism, October 2005

1560 Robert Dur and Amihai Glazer, Subsidizing Enjoyable Education, October 2005

1561 Carlo Altavilla and Paul De Grauwe, Non-Linearities in the Relation between the Exchange Rate and its Fundamentals, October 2005

1562 Josef Falkinger and Volker Grossmann, Distribution of Natural Resources, Entrepreneurship, and Economic Development: Growth Dynamics with Two Elites, October 2005

$1563 \mathrm{Yu}-\mathrm{Fu}$ Chen and Michael Funke, Product Market Competition, Investment and Employment-Abundant versus Job-Poor Growth: A Real Options Perspective, October 2005

1564 Kai A. Konrad and Dan Kovenock, Equilibrium and Efficiency in the Tug-of-War, October 2005

1565 Joerg Breitung and M. Hashem Pesaran, Unit Roots and Cointegration in Panels, October 2005

1566 Steven Brakman, Harry Garretsen and Marc Schramm, Putting New Economic Geography to the Test: Free-ness of Trade and Agglomeration in the EU Regions, October 2005

1567 Robert Haveman, Karen Holden, Barbara Wolfe and Andrei Romanov, Assessing the Maintenance of Savings Sufficiency Over the First Decade of Retirement, October 2005

1568 Hans Fehr and Christian Habermann, Risk Sharing and Efficiency Implications of Progressive Pension Arrangements, October 2005

1569 Jovan Žamac, Pension Design when Fertility Fluctuates: The Role of Capital Mobility and Education Financing, October 2005

1570 Piotr Wdowinski and Aneta Zglinska-Pietrzak, The Warsaw Stock Exchange Index WIG: Modelling and Forecasting, October 2005 
1571 J. Ignacio Conde-Ruiz, Vincenzo Galasso and Paola Profeta, Early Retirement and Social Security: A Long Term Perspective, October 2005

1572 Johannes Binswanger, Risk Management of Pension Systems from the Perspective of Loss Aversion, October 2005

1573 Geir B. Asheim, Wolfgang Buchholz, John M. Hartwick, Tapan Mitra and Cees Withagen, Constant Savings Rates and Quasi-Arithmetic Population Growth under Exhaustible Resource Constraints, October 2005

1574 Christian Hagist, Norbert Klusen, Andreas Plate and Bernd Raffelhueschen, Social Health Insurance - the Major Driver of Unsustainable Fiscal Policy?, October 2005

1575 Roland Hodler and Kurt Schmidheiny, How Fiscal Decentralization Flattens Progressive Taxes, October 2005

1576 George W. Evans, Seppo Honkapohja and Noah Williams, Generalized Stochastic Gradient Learning, October 2005

1577 Torben M. Andersen, Social Security and Longevity, October 2005

1578 Kai A. Konrad and Stergios Skaperdas, The Market for Protection and the Origin of the State, October 2005

1579 Jan K. Brueckner and Stuart S. Rosenthal, Gentrification and Neighborhood Housing Cycles: Will America’s Future Downtowns be Rich?, October 2005

1580 Elke J. Jahn and Wolfgang Ochel, Contracting Out Temporary Help Services in Germany, November 2005

1581 Astri Muren and Sten Nyberg, Young Liberals and Old Conservatives - Inequality, Mobility and Redistribution, November 2005

1582 Volker Nitsch, State Visits and International Trade, November 2005

1583 Alessandra Casella, Thomas Palfrey and Raymond Riezman, Minorities and Storable Votes, November 2005

1584 Sascha O. Becker, Introducing Time-to-Educate in a Job Search Model, November 2005

1585 Christos Kotsogiannis and Robert Schwager, On the Incentives to Experiment in Federations, November 2005

1586 Søren Bo Nielsen, Pascalis Raimondos-Møller and Guttorm Schjelderup, Centralized vs. De-centralized Multinationals and Taxes, November 2005

1587 Jan-Egbert Sturm and Barry Williams, What Determines Differences in Foreign Bank Efficiency? Australian Evidence, November 2005 
1588 Steven Brakman and Charles van Marrewijk, Transfers, Non-Traded Goods, and Unemployment: An Analysis of the Keynes - Ohlin Debate, November 2005

1589 Kazuo Ogawa, Elmer Sterken and Ichiro Tokutsu, Bank Control and the Number of Bank Relations of Japanese Firms, November 2005

1590 Bruno Parigi and Loriana Pelizzon, Diversification and Ownership Concentration, November 2005

1591 Claude Crampes, Carole Haritchabalet and Bruno Jullien, Advertising, Competition and Entry in Media Industries, November 2005

1592 Johannes Becker and Clemens Fuest, Optimal Tax Policy when Firms are Internationally Mobile, November 2005

1593 Jim Malley, Apostolis Philippopoulos and Ulrich Woitek, Electoral Uncertainty, Fiscal Policy and Macroeconomic Fluctuations, November 2005

1594 Assar Lindbeck, Sustainable Social Spending, November 2005

1595 Hartmut Egger and Udo Kreickemeier, International Fragmentation: Boon or Bane for Domestic Employment?, November 2005

1596 Martin Werding, Survivor Benefits and the Gender Tax Gap in Public Pension Schemes: Observations from Germany, November 2005

1597 Petra Geraats, Transparency of Monetary Policy: Theory and Practice, November 2005

1598 Christian Dustman and Francesca Fabbri, Gender and Ethnicity - Married Immigrants in Britain, November 2005

1599 M. Hashem Pesaran and Martin Weale, Survey Expectations, November 2005

1600 Ansgar Belke, Frank Baumgaertner, Friedrich Schneider and Ralph Setzer, The Different Extent of Privatisation Proceeds in EU Countries: A Preliminary Explanation Using a Public Choice Approach, November 2005

1601 Jan K. Brueckner, Fiscal Federalism and Economic Growth, November 2005

1602 Steven Brakman, Harry Garretsen and Charles van Marrewijk, Cross-Border Mergers and Acquisitions: On Revealed Comparative Advantage and Merger Waves, November 2005

1603 Erkki Koskela and Rune Stenbacka, Product Market Competition, Profit Sharing and Equilibrium Unemployment, November 2005

1604 Lutz Hendricks, How Important is Discount Rate Heterogeneity for Wealth Inequality?, November 2005 
1605 Kathleen M. Day and Stanley L. Winer, Policy-induced Internal Migration: An Empirical Investigation of the Canadian Case, November 2005

1606 Paul De Grauwe and Cláudia Costa Storti, Is Monetary Policy in the Eurozone less Effective than in the US?, November 2005

1607 Per Engström and Bertil Holmlund, Worker Absenteeism in Search Equilibrium, November 2005

1608 Daniele Checchi and Cecilia García-Peñalosa, Labour Market Institutions and the Personal Distribution of Income in the OECD, November 2005

1609 Kai A. Konrad and Wolfgang Leininger, The Generalized Stackelberg Equilibrium of the All-Pay Auction with Complete Information, November 2005

1610 Monika Buetler and Federica Teppa, Should you Take a Lump-Sum or Annuitize? Results from Swiss Pension Funds, November 2005

1611 Alexander W. Cappelen, Astri D. Hole, Erik Ø. Sørensen and Bertil Tungodden, The Pluralism of Fairness Ideals: An Experimental Approach, December 2005

1612 Jack Mintz and Alfons J. Weichenrieder, Taxation and the Financial Structure of German Outbound FDI, December 2005

1613 Rosanne Altshuler and Harry Grubert, The Three Parties in the Race to the Bottom: Host Governments, Home Governments and Multinational Companies, December 2005

1614 Chi-Yung (Eric) Ng and John Whalley, Visas and Work Permits: Possible Global Negotiating Initiatives, December 2005

1615 Jon H. Fiva, New Evidence on Fiscal Decentralization and the Size of Government, December 2005

1616 Andzelika Lorentowicz, Dalia Marin and Alexander Raubold, Is Human Capital Losing from Outsourcing? Evidence for Austria and Poland, December 2005

1617 Aleksander Berentsen, Gabriele Camera and Christopher Waller, Money, Credit and Banking, December 2005

1618 Egil Matsen, Tommy Sveen and Ragnar Torvik, Savers, Spenders and Fiscal Policy in a Small Open Economy, December 2005

1619 Laszlo Goerke and Markus Pannenberg, Severance Pay and the Shadow of the Law: Evidence for West Germany, December 2005

1620 Michael Hoel, Concerns for Equity and the Optimal Co-Payments for Publicly Provided Health Care, December 2005

1621 Edward Castronova, On the Research Value of Large Games: Natural Experiments in Norrath and Camelot, December 2005 